\title{
Health-Related Suffering and Palliative Care in Breast Cancer
}

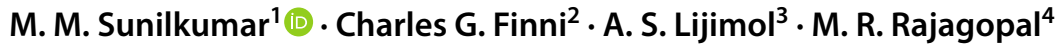

Accepted: 18 September 2021 / Published online: 16 November 2021

(c) The Author(s), under exclusive licence to Springer Science+Business Media, LLC, part of Springer Nature 2021

\begin{abstract}
Purpose of Review Breast cancer continues to be the most frequently diagnosed cancer in women and the leading cause of cancer death worldwide. By the suffering that it causes in various domains of life, breast cancer seriously impacts the quality of life of affected individuals and causes a major burden of suffering in the community. The objectives of the review were to understand the health-related suffering in patients with breast cancer and to identify the scope of palliative care in improving the quality of life of patients with breast cancer.

Recent Findings Breast cancer causes suffering in physical, psychological, social, financial, and spiritual domains of the lives of the patient and family. Management of breast cancer with surgery, chemotherapy, and radiation could have adverse effects, such as pain, nausea and vomiting, fatigue, shortness of breath, depression, and constipation. Both cancer and its treatment can impact the psychosocial and spiritual well-being of the patient and family members. Integrating palliative care into existing breast cancer treatment programs seems to be the best approach to diminish these sufferings.

Summary In addition to pain and other physical symptoms, breast cancer can cause major psychological, social, and spiritual suffering. In the context of developing countries, out-of-pocket expenditure can cause major financial destruction which can impact generations. Integration of palliative care to breast cancer treatment is essential.
\end{abstract}

Keywords Breast cancer · Palliative care $\cdot$ Health related sufferings · Quality of life · Pain

This article is part of the Topical Collection on Breast Cancer Management During the COVID-19 Pandemic

M. M. Sunilkumar

sunil@palliumindia.org

Charles G. Finni

gcharles.finni@gmail.com

A. S. Lijimol

liji@palliumindia.org

M. R. Rajagopal

chairman@palliumindia.org

1 Palliative care center \& Academics, Trivandrum Institute of Palliative Sciences (TIPS), WHO Collaborating Centre for Training and Policy On Access To Pain Relief, Pallium India, Aisha Memorial Hospital Building, Manacaud P.O., Paruthikkuzhy, Thiruvananthapuram 695009, Kerala, India

2 Projects (Ex-staff), Trivandrum Institute of Palliative Sciences (TIPS), WHO Collaborating Centre for Training and Policy On Access To Pain Relief, Pallium India, Aisha Memorial Hospital Building, Manacaud P.O., Paruthikkuzhy, Thiruvananthapuram 695009, Kerala, India
3 Academics, Trivandrum Institute of Palliative Sciences (TIPS), WHO Collaborating Centre for Training and Policy On Access To Pain Relief, Pallium India, Aisha Memorial Hospital Building, Manacaud P.O., Paruthikkuzhy, Thiruvananthapuram 695009, Kerala, India

4 Director, Trivandrum Institute of Palliative Sciences (TIPS), WHO Collaborating Centre for Training and Policy On Access To Pain Relief, Pallium India, Aisha Memorial Hospital Building, Manacaud P.O., Paruthikkuzhy, Thiruvananthapuram 695009, Kerala, India 


\section{Introduction}

Breast cancer is the most frequently diagnosed cancer in women and the leading cause of cancer-related death in women worldwide $[1,2]$. While the incidence rate of this disease tends to be higher in high-income countries, lowto-middle-income countries (LMICs) shoulder a disproportionate mortality burden from this disease in part because of their higher population and the late presentation of the disease in these settings. It has been suggested that over 19.5 million new cases of breast cancer will be diagnosed among women globally by the year 2024, of which $55 \%$ will occur in LMICs [3]. Most breast cancer patients (50-80\%) in LMICs present with advanced or metastatic disease, as opposed to high-income countries where the figure is much lower (10-15\%). This finding is often associated with fewer treatment options, higher costs, no cure, and more suffering [4].

Women's suffering can be increased in all domains of life due to breast cancer. The health-related suffering of breast cancer has different facets such as physical, psychosocial, financial, and spiritual [5]. This warrants a methodical approach to the assessment of each specific issue, by a welltrained and organized clinical team including physicians, nurses, and different therapists.

The patient may have undergone surgery, chemotherapy, and/or radiation therapy which may have caused side effects such as pain, nausea, vomiting, fatigue, shortness of breath, constipation, hair loss, skin problems, and lymphedema [6, 7]. Treatment can also impact the psychosocial well-being of the patient and family members. Patients diagnosed as having progressive breast cancer and their caregivers have complex needs that should be assessed and managed properly to reduce the severity of suffering, distress, and deterioration in the quality of life of patients and caregivers. This mission needs the complete commitment of an interdisciplinary approach to palliative care [8].

In most parts of India, cancer treatment is paid for out of pocket (OOP), which can push families to below the poverty line [9•]. Out-of-pocket (OOP) expenditures account for more than three-quarters of cancer spending in India. Catastrophic health expenditure (CHEs) affects not only the patient, but also the family as a whole [10]. A cross-sectional study in India found out that about $84 \%$ of the families with patients diagnosed with breast cancer are susceptible to catastrophic health expenditure (CHE) and nearly $50 \%$ of the families had met with financial hardships during cancer treatment [9•].

The notion of suffering in a medical context has been expounded upon by Casell in 1982. Casell distinguished that suffering is an experience of the whole person, while medicine, by and large, tends to focus only on the body [11].
There are often different treatment modalities, all with a similar response to treatment and survival rates, but that vary with their physical and emotional consequences for the woman. Psychological, sexual, and physical dysfunction caused by diagnostics and treatment of cancer can seriously impact the women's quality of life adversely. Not to recognize a human being as an entity of body, soul, and spirit can prevent the easing of suffering that patients may face.

\section{Physical Suffering in Breast Cancer}

Physical suffering related to breast cancer comprises pain, breathlessness, fatigue, breast ulceration, changes in body appearance, menopause-related symptoms, fertility, and other reproductive problems and lymphedema $[8,12,13]$.

\section{Pain}

Pain is not a common symptom at the early stage of breast cancer but as it advances, advanced disease can lead to pain by the involvement of muscles and ribs [14]. The treatment of pain can be done using the WHO analgesic ladder and addressing the psychosocial and spiritual concerns of the patient. In addition, interventional pain management can also be used when appropriate. Persistent pain after breast cancer treatment (PPBCT) is an important issue that needs to be addressed as it affects about $25-60 \%$ of patients [15]. Whether patients are treated with surgery alone, or in combination with radiotherapy, results in roughly the same amount of pain because both involve damage to nerves which then cause a variety of problems like pain, numbness, and reduced movements of arm, hand, and shoulder [16-18]. This pain can become persistent, potentially causing lifelong suffering $[19,20]$. The main factors implicated in the development of chronic post-mastectomy pain include injury to intercostobrachial nerves, surgical scar, neuroma formation, emotional factors, and phantom breast pain [19, 21]. The application of morphine locally before wound closure has been shown to reduce the development of severity and incidence of chronic post-mastectomy pain [22]. Various treatments have been proposed for the treatment of persistent post-mastectomy pain which includes amitriptyline, venlafaxine, and 5\% lidocaine patches [23-25]. A doubleblind randomized control study with pregabalin $75 \mathrm{mg}$ twice daily, when started the morning of surgery and continued for 1 week, has shown that this regimen reduces chronic postmastectomy pain [26•].

\section{Physical Appearance}

Irrespective of the mode of treatment or how the body looks subsequent to treatment, a woman is likely to feel differently about her physique after the management of breast cancer. 
Most women are concerned with their body image, and breast cancer surgery can affect a woman's self-confidence and relationship with others, especially with her spouse [12].

\section{Menopause-Related Symptoms}

Breast cancer treatment like chemotherapy, hormonal therapy, or ovarian suppression can lead to menopausal symptoms such as hot flushes, night sweats, vaginal dryness, palpitations, mood changes, joint pain, and changes to skin and hair [27]. Most women find it difficult to cope or adapt to these issues with resultant worsening of their quality of life. Menopausal symptoms are usually severe due to the sudden and quick reduction in estrogen. There is a lack of scientific evidence about the effectiveness of complementary therapies [28]. For patients with mild vasomotor symptoms, behavioral modification and yoga may be helpful, while newer antidepressants are likely to be effective in moderate to severe cases. In refractory cases, stellate ganglion block may be used [28]. Local vaginal moisturizers, and low-dose estrogen creams in patients with refractory symptoms, can help in the management of most urogenital symptoms. Early menopause can also cause decreased bone mineral density; this can be improved with weight-bearing exercises, calcium, vitamin D, and bisphosphonates.[28].

\section{Fertility and Other Reproductive Problems}

Chemotherapy can adversely affect the reproductive function of women [29]. Nearly 3\% of breast cancers occur in women during the reproductive age of 25-35 years [30]. These patients should consult reproductive experts to discuss issues around fertility and menopause prior to initiation of chemotherapy. Fertility preservation is possible by removing and preserving ovarian tissue or mature oocytes prior to chemotherapy or by preserving fertilized embryos for future use [31].

\section{Lymphedema}

Lymph node surgery and radiation therapy can disrupt lymphatics and result in lymph stasis and lymphedema [32]. This can affect the treated side in the hand, arm, underarm, chest, and upper back causing discomfort and swelling [33]. Lymphedema can also lead to psychosocial issues that negatively affect breast cancer survivors' day-to-day lives [34, 35]. Women who develop lymphedema have higher health care costs than those without it, and this could also negatively affect their job and day-to-day life [36]. Lymphedema can often be managed with massage, physical therapy (including weight-bearing exercises), and, if needed, compression garments.

\section{Psychosocial Suffering}

The diagnosis of breast cancer is a shocking news for most women, after which, the emotional response ranges anywhere from despair to rage. For some patients, there can be deterioration in psychological well-being [37], with symptoms of post-traumatic stress [38] that can persist for over a year.

The psychological issues faced by such women include:

\section{Depression}

One of the most common psychological issues faced by women with breast cancer is depression [39], which is often driven by the fear of cancer recurrence or metastases [40].

Anxiety

Anxiety is typically associated with cancer and it is the most predominant psychological symptom perceived by cancer patients [41]. A study by Ashbury et al. showed that more than half of the patients recalled experiencing anxiety within 2 years of treatment of cancer [42]. This tends to be worse with stage and more intensive treatment.

\section{Quality of Life}

Patients diagnosed with breast cancer experience physical symptoms and psychosocial distress that negatively impact their quality of life (QOL). QOL usually involves various domains including physical functioning, psychological well-being, and social support [43]. Pain is the most common physical symptom impacting their quality of life [44]. Gangane et al. in a 2017 study of breast cancer patients in central rural India found that young age, lack of education, and being without a partner were associated with a lower QOL while employment, higher monthly family income, higher self-efficacy, and social, financial and environmental support were associated with a higher QOL [45]. The physical, psychological, and emotional well-being of breast cancer patients can be improved by physical activity thereby improving the quality of life of these patients [46].

\section{Positive Psychological Adaptation: Resilience}

Psychological resilience is the capacity of a person to protect his/her psychological health when faced with difficulty such as cancer diagnosis in their life. Psychological resilience affects diverse aspects of health-related quality of life in breast cancer patients. Patients with more resilience have a notably better quality of life in almost all domains [47]. Strategies like stress management, resilience 
training, meaning-making interventions, and self-efficacy may improve patients' resilience [48].

\section{Palliative Care for Breast Cancer}

According to WHO, "palliative care is an approach that improves quality of life of patients and their families facing the problems associated with life threatening illness through prevention and relief of suffering by means of early identification and impeccable assessment and treatment of pain and other problems such as physical, psychosocial and spiritual." [49]

As WHO pointed out, palliative care gives relief from pain and other health-related symptoms and sufferings. Palliative care aims neither to hasten nor postpone death and it considers dying as a normal process in life. Palliative care uses a team approach to address the needs of patients and their families, including bereavement counseling if indicated, enhances the quality of life, and may also positively influence the course of illness. Palliative care is not just end-of-life care, it is applicable from the diagnosis of an illness, in conjunction with other therapies that are planned and implemented to prolong life, such as chemotherapy or radiation therapy [49].

Palliative care is often a low priority in low- and middle-income countries [50]. Zimmerman et al. in a cluster randomized trial looked at providing early palliative care in metastatic cancer, including breast cancer. They demonstrated immediate improvement of satisfaction with care but improvement in quality of life was most marked at 4 months of starting palliative care intervention [51]. Vanbutsele et al. similarly found, in a randomized control trial among advanced cancer patients, that the early and systematic integration of palliative care into cancer care resulted in significantly improved quality of life at 12 and 18 weeks of regular

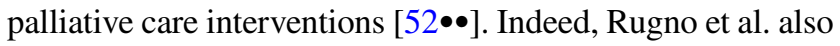
found that earlier consultation with a palliative care team lowered rates of depression and improved quality of life and survival [53]. Failure to provide palliative care during cancer treatment can lead to increased non-compliance and worsened outcomes, thereby diminishing the value of therapeutic interventions [54].

\section{Conclusion}

The main emphasis of palliative care is on the prevention and management of breast cancer symptoms and the side effects of treatment, along with psychosocial and spiritual support. Palliative care can improve the quality of life of patients with breast cancer and their families through the management of health-related suffering. It concentrates on a holistic approach and encompasses a variety of services for patients and their relatives. It can be initiated as early as the time of diagnosis and continue through to end-of-life care and bereavement. Integrating palliative care in the treatment of breast cancer can improve the quality of life of the patient and the family as a whole.

\section{Declarations}

Human and Animal Rights and Informed Consent This article does not contain any studies with human or animal subjects performed by any of the authors.

Conflict of Interest The authors declare no competing interests.

\section{References}

Papers of particular interest, published recently, have been highlighted as:

- Of importance

$\bullet$ Of major importance

1. Bray F, Ferlay J, Soerjomataram I, Siegel RL, Torre LA, Jemal A. Global cancer statistics 2018: GLOBOCAN estimates of incidence and mortality worldwide for 36 cancers in 185 countries. CA Cancer J Clin. 2018;68(6):394-424.

2. Addressing the Global Burden of Breast Cancer [Internet]. National Cancer Institute. 2017 [cited 2019 Apr 18]

3. Anderson BO. UICC World Cancer Congress 2014: global breast cancer trends. In: Washington: the breast health global initiative; 2014. p. $1-10$

4. Unger-Saldaña K. Challenges to the early diagnosed and treatment of breast cancer in developing countries. World Journal of Clinical Oncology. 2014;5(3):465-77.

5. Ataollahi M, Sharifi J, Paknahad M, Paknahad A. Breast cancer and associated factors: a review. J Med Life. 2015;8(Spec Iss 4):6-11.

6. Agrawal S. Late effects of cancer treatment in breast cancer survivors. South Asian J Cancer. 2014;3(2):112-5.

7. Radiation Therapy Side Effects [Internet]. [cited $2020 \mathrm{Feb} 28$ ]. Available from: https://www.cancer.org/treatment/treatmentsand-side-effects/treatment-types/radiation/effects-on-differentparts-of-body.html

8. Cherny NI, Paluch-Shimon S, Berner-Wygoda Y. Palliative care: needs of advanced breast cancer patients. Breast Cancer (Dove Med Press). 2018;10:231-43.

9. Jain M, Mukherjee K. Economic burden of breast cancer to the households in Punjab, India. International Journal of Medicine and Public Health. 2016;6(1):13-8. (This study from a low middle income country describes economic burden of treatment of breast cancer.)

10 Rajpal S, Kumar A, Joe W. Economic burden of cancer in India: evidence from cross-sectional nationally representative household survey. PLOS ONE. 2014;13(2):e0193320.

11. Cassel EJ. The nature of suffering and the goals of medicine. $\mathrm{N}$ Engl J Med. 1982;306(11):639-45. 
12. Managing physical changes due to breast cancer I Breast cancer [Internet]. [cited2019 May 27]. Availablefrom:https://breastcanc er.canceraustralia.gov.au/living/physical-changes

13. Galipeau N, Klooster B, Krohe M, Tang DH, Revicki DA, Cella D. Understanding key symptoms, side effects, and impacts of HR+/HER2-advanced breast cancer: qualitative study findings. Journal of patient-reported outcomes. 2019;3(1):10.

14. Satija A, Ahmed SM, Gupta R, Ahmed A, Rana SP, Singh SP, Mishra S, Bhatnagar S. Breast cancer pain managementA review of current \& novel therapies. Indian J Med Res. 2014;139(2):216.

15. Wang K, Yee C, Tam S, Drost L, Chan S, Zaki P, Rico V, Ariello K, Dasios M, Lam H, DeAngelis C. Prevalence of pain in patients with breast cancer post-treatment: a systematic review. The Breast. 2018

16 Rietman JS, Dijkstra PU, Hoekstra HJ, et al. Late morbidity after treatment of breast cancer in relation to daily activities and quality of life: a systematic review. Eur J Surg Oncol. 2003;29(3):229e38.

17 Andersen KG, Duriaud HM, Jensen HE, Kroman N, Kehlet H. Predictive factorsfor the development of persistent pain after breast cancer surgery. Pain. 2015;156(12):2413e22.

18. Poleshuck EL, Katz J, Andrus CH, et al. Risk factors for chronic pain following breast cancer surgery: a prospective study. J Pain. 2006;7(9):626e34.

19. Jung BF, Ahrendt GM, Oaklander AL, Dworkin RH. Neuropathic pain following breast cancer surgery: proposed classification and research update. Pain. 2003;104:1-13.

20. Haroutiunian S, Nikolajsen L, Finnerup NB, Jensen TS. The neuropathic component in persistent postsurgical pain: a systematic literature review. Pain. 2013;154:95-102.

21. Kaur N, Jain A. Postmastectomy chronic pain in breast cancer survivors: an update on definition, pathogenesis, risk Factors, treatment and prevention. Clin Oncol. 2017;2:1300.

22. Mohamed SA, Abdel-Ghaffar HS, Kamal SM, Fares KM, Hamza HM. Effect of topical morphine on acute and chronic postmastectomy pain: what is the optimum dose? Reg Anesth Pain Med. 2016;41(6):704-10.

23. Tasmuth T, Härtel B, Kalso E. Venlafaxine in neuropathic pain following treatment of breast cancer. Eur J Pain. 2002;6(1):17-24.

24. Kalso E, Tasmuth T, Neuvonen PJ. Amitriptyline effectively relieves neuropathic pain following treatment of breast cancer. Pain. 1996;64(2):293-302.

25. Cruto ME, Baricocchi E, Battistella M, Bona F, Giacoletto $\mathrm{G}$, Iacobellis A, et al. Treatment of persistent postmastectomy pain with $5 \%$ lidocaine medicated plaster. Minerva Chir. 2015;70(2):147-53

26.• Reyad RM, Omran AF, Abbas DN, Kamel MA, Shaker EH, Tharwat J, Reyad EM, Hashem T. The possible preventive role of pregabalin in postmastectomy pain syndrome: a doubleblinded randomized controlled trial. J Pain Symptom Manage. 2019;57(1):1-9. (. This double-blinded randomised controlled trial describes the effect of Pregabalin when used perioperatively can reduce the occurrence of post mastectomy pain.)

27. Menopausal symptoms and breast cancer I Breast Cancer Care [Internet]. [cited 2019 May 27]. Available,from:https://www. breastcancercare.org.uk/information-support/facing-breast-cancer/going-through-treatment-breast-cancer/side-effects/menop ausal-symptoms-after-treatment

28. Murthy V, Chamberlain RS. Menopausal symptoms in young survivors of breast cancer: a growing problem without an ideal solution. Cancer Control. 2012;19(4):317-29.

29. How cancer treatments can affect fertility in women [Internet]. [cited $2020 \mathrm{Feb} 29]$ ]. Available from: https://www.cancer.org/ treatment/treatments-and-side-effects/physical-side-effects/ferti lity-and-sexual-side-effects/fertility-and-women-with-cancer/ how-cancer-treatments-affect-fertility.html

30. Surveillance Epidemiology and End Results Program. Surveillance, epidemiology and end results program public use CDROM. Bethesda, MD: National Cancer Institute; 2000

31. Hickey M, Peate M, Saunders CM, Friedlander M. Breast cancer in young women and its impact on reproductive function. Hum Reprod Update. 2009;15(3):323-39. https://doi.org/10.1093/ humupd/dmn064.

32. Breast Cancer: Lymphedema After Treatment I Johns Hopkins Medicine [Internet]. [cited 2020 Feb 5]. Available from: https:// www.hopkinsmedicine.org/health/conditions-and-diseases/ breast-cancer/breast-cancer-lymphedema-after-treatment

33. How Lymphedema Happens I Breastcancer.org [Internet]. [cited 2019 May 27]. Available from: https://www.breastcancer.org/ treatment/lymphedema/how

34. Fu MR, Kang Y. Psychosocial impact of living with cancerrelated lymphedema. Semin Oncol Nurs. 2013;29:50-60.

35. Fu MR, Rosedale M. Breast cancer survivors' experiences of lymphedema-related symptoms. J Pain Symptom Manage. 2009;38:849-59.

36. Shih YC, Xu Y, Cormier JN, Giordano S, Ridner SH, Buchholz TA, Perkins GH, Elting LS. Incidence, treatment costs, and complications of lymphedema after breast cancer among women of working age: a 2-year follow-up study. J Clin Oncol. 2009;27:2007-14.

37. How can a breast cancer diagnosis play havoc with your emotions? [Internet]. Verywell Health. [cited 2020 Feb 5]. Available from: https://www.verywellhealth.com/the-psychologicalimpact-of-a-breast-cancer-diagnosis-430338

38. Mehnert A, Koch U. Prevalence of acute and post-traumatic stress disorder and comorbid mental disorders in breast cancer patients during primary cancer care: a prospective study. Psychooncology. 2007;16(3):181-8.

39. Ng CG, Mohamed S, Kaur K, Sulaiman AH, Zainal NZ, Taib NA, et al. Perceived distress and its association with depression and anxiety in breast cancer patients. PLoS ONE. 2017;12(3):e0172975.

40. Pan L, Han Y, Sun X, Liu J, Gang H. FDG-PET and other imaging modalities for the evaluation of breast cancer recurrence and metastases: a meta-analysis. J Cancer Res Clin Oncol. 2010;136(7):1007-22.

41. Takahashi T, Hondo M, Nishimura K, Kitani A, Yamano T, Yanagita $\mathrm{H}$, et al. Evaluation of quality of life and psychological response in cancer patients treated with radiotherapy. Radiat Med. 2008;26(7):396-401.

42. Ashbury FD, Findlay H, Reynolds B, McKerracher K. A Canadian survey of cancer patients' experiences: are their needs being met? J Pain Symptom Manage. 1998;16(5):298-306.

43. Perry S, Kowalski TL, Chang C-H. Quality of life assessment in women with breast cancer: benefits, acceptability and utilization. Health Qual Life Outcomes. 2007;5:24.

44. Costa WA, Monteiro MN, Queiroz JF, Gonçalves AK. Pain and quality of life in breast cancer patients. Clinics (Sao Paulo). 2017;72(12):758-63.

45. Gangane N, Khairkar P, Hurtig A-K, Sebastián MS. Quality of life determinants in breast cancer patients in Central Rural India. Asian Pac J Cancer Prev. 2017;18(12):3325-32.

46. Leclerc A-F, Jerusalem G, Devos M, Crielaard J-M, Maquet D. Multidisciplinary management of breast cancer. Arch Public Health [Internet]. 2016 Dec 5 [cited 2020 Feb 5];74. Available from: https://www.ncbi.nlm.nih.gov/pmc/articles/PMC5137213/

47. Ristevska-Dimitrovska G, Filov I, Rajchanovska D, Stefanovski P, Dejanova B. Resilience and quality of life in breast cancer patients. Open Access Maced J Med Sci. 2015;3(4):727-31. 
48. Molina Y, Yi JC, Martinez-Gutierrez J, Reding KW, Yi-Frazier JP, Rosenberg AR. Resilience among patients across the cancer continuum: diverse perspectives. Clin J Oncol Nurs. 2014;18(1):93-101.

49. WHO / WHO Definition of Palliative Care [Internet]. WHO. [cited 2020 Feb 5]. Available from: https://www.who.int/cancer/ palliative/definition/en/

50. Anderson RE, Grant L. What is the value of palliative care provision in low-resource settings? BMJ Glob Health [Internet]. 2017 Feb 14 [cited 2020 Mar 2];2(1).

51 Zimmermann C, Swami N, Rodin G, Tannock I, Krzyzanowska MK, Leighl NB, et al. Cluster-randomized trial of early palliative care for patients with metastatic cancer. JCO. 2012;30(15_suppl):9003-9003.

52.• Vanbutsele G, Pardon K, Van Belle S, Surmont V, De Laat M, Colman R, et al. Effect of early and systematic integration of palliative care in patients with advanced cancer: a randomised controlled trial. Lancet Oncol. 2018;19(3):394-404. (This randomised controlled trial describes the importance of integration of palliative care into advanced cancer care for improving the quality of life.)

53. Rugno FC, Paiva BS, Paiva CE. Early integration of palliative care facilitates the discontinuation of anticancer treatment in women with advanced breast or gynecologic cancers. Gynecol Oncol. 2014;135(2):249-54.

54. Supportive care during treatment for breast cancer: resource allocations in low- and middle-income countries. A Breast Health Global Initiative 2013 consensus statement - The Breast [Internet]. [cited $2020 \mathrm{Feb} 5]$. Available from: https://www.thebreasto nline.com/article/S0960-9776(13)00215-4/fulltext

Publisher's Note Springer Nature remains neutral with regard to jurisdictional claims in published maps and institutional affiliations. 